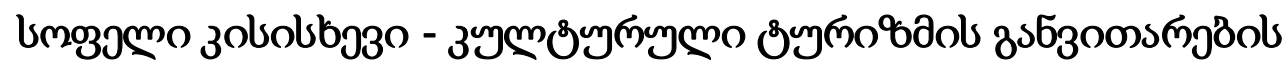 usy3joglum ngluymb
}

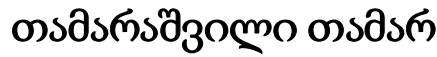

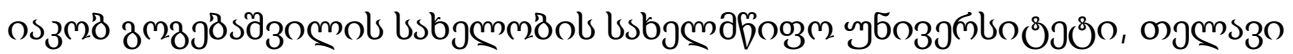

https://doi.org/10.52340/idw.2021.528

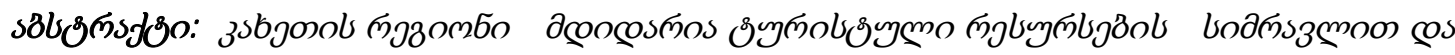

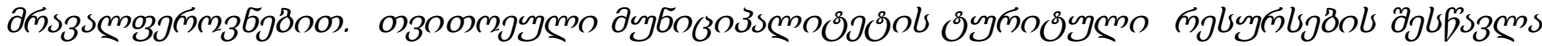

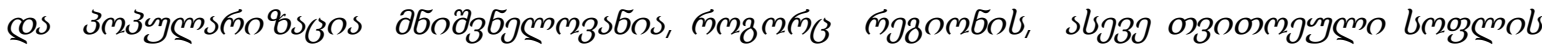

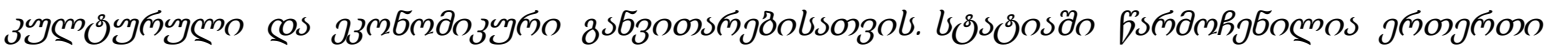

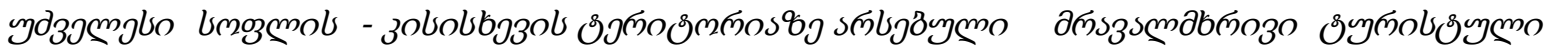

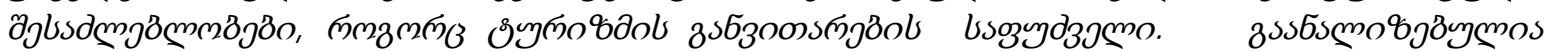

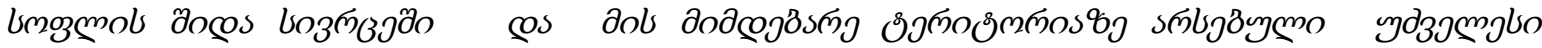

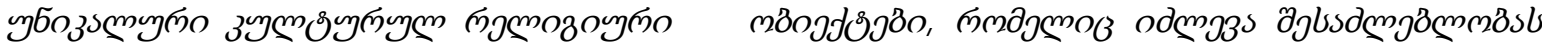

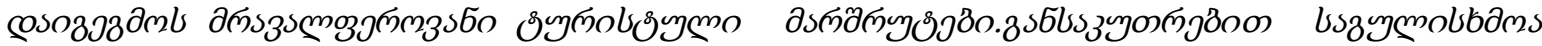

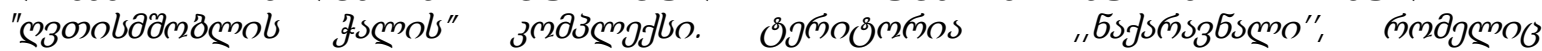

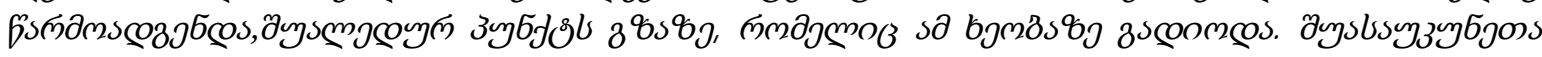

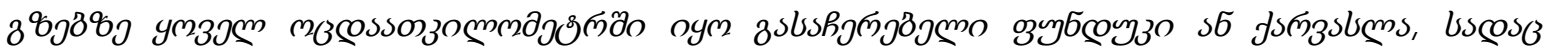

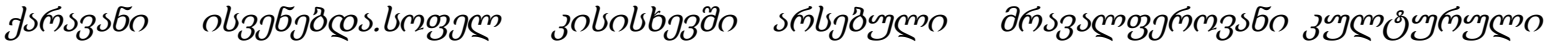

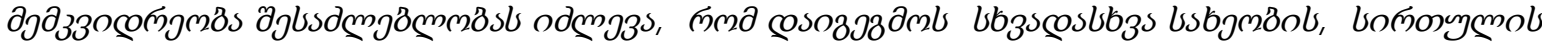

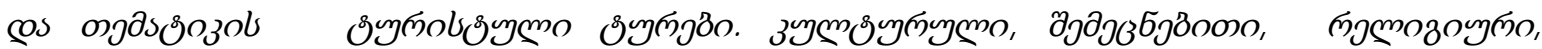

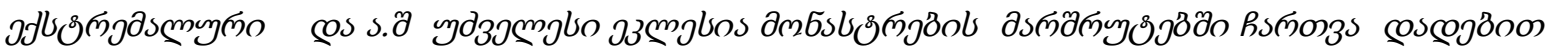

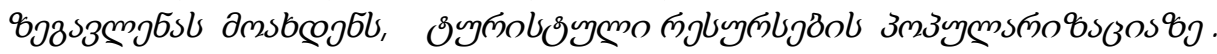

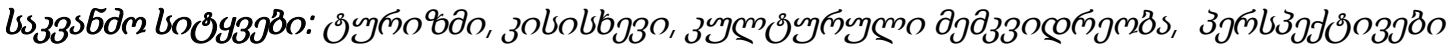

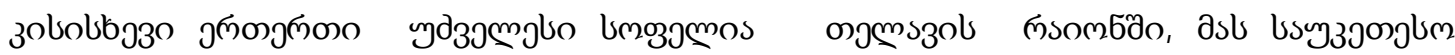

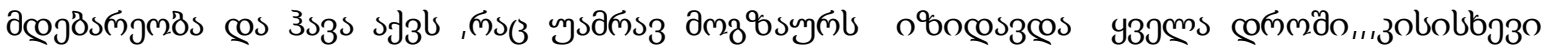

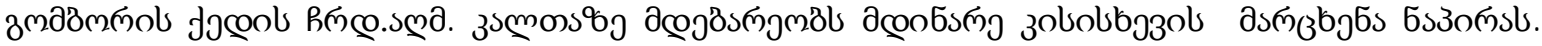

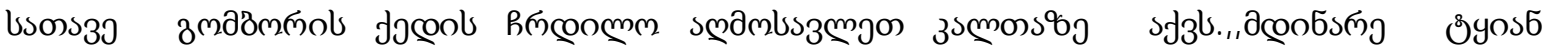

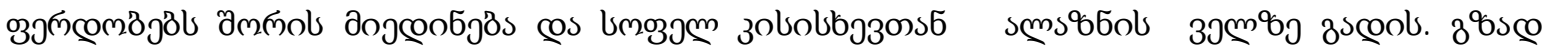

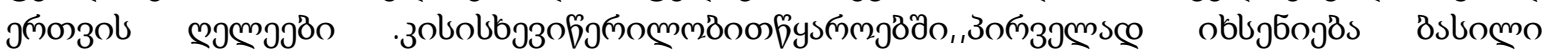

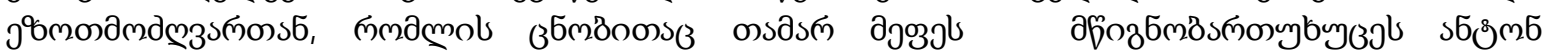

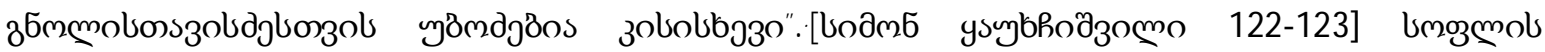

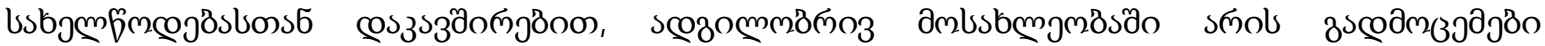

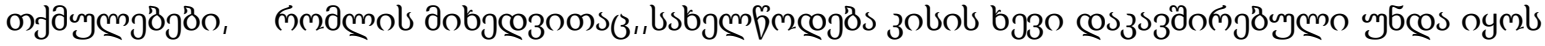

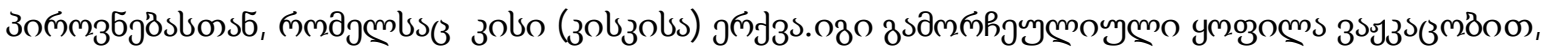

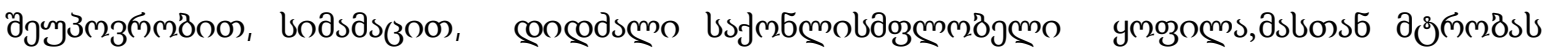

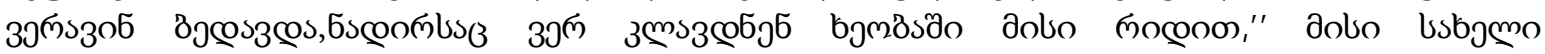

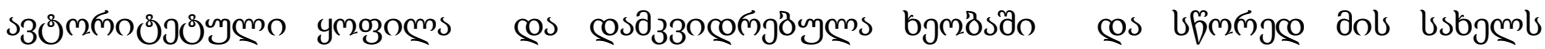

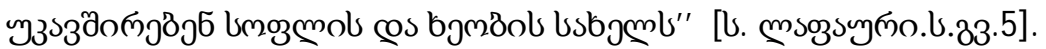

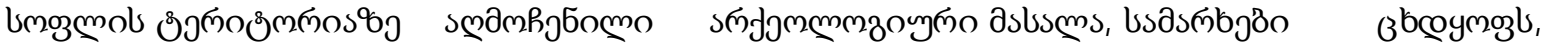




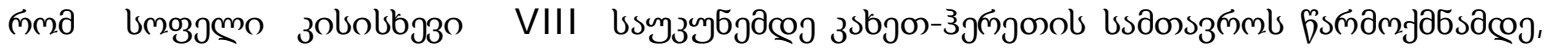

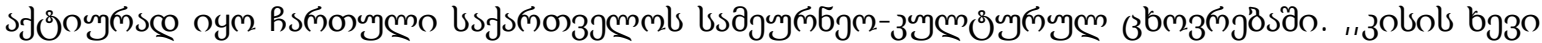

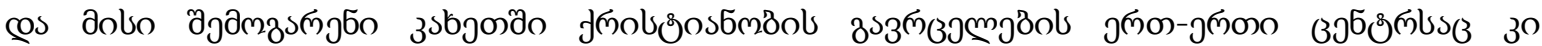

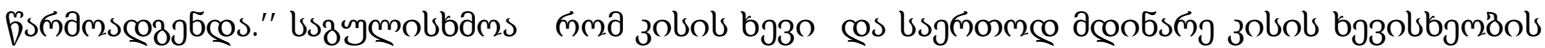

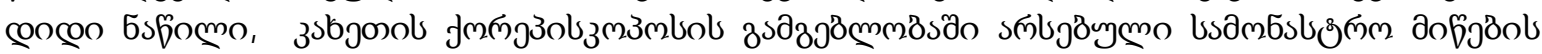

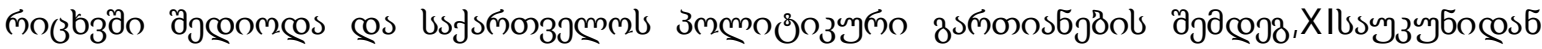

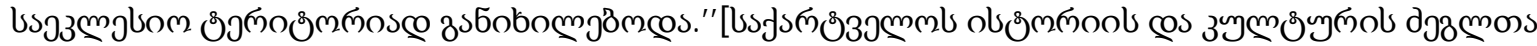
sल6эॅомм8s 33252]

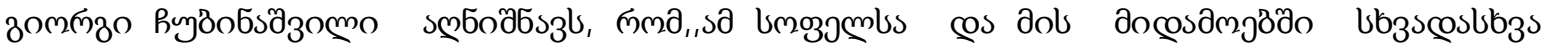

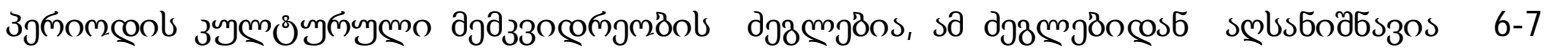

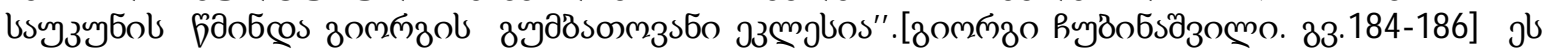

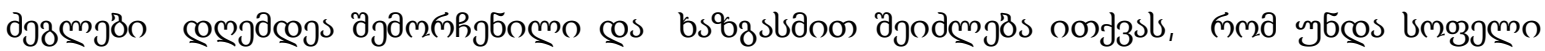

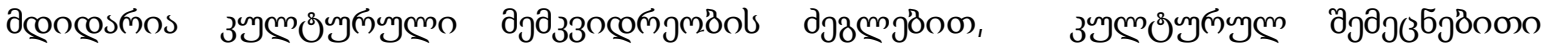

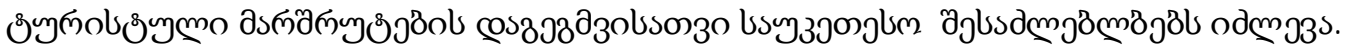

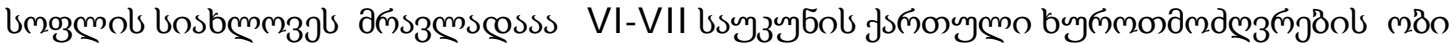

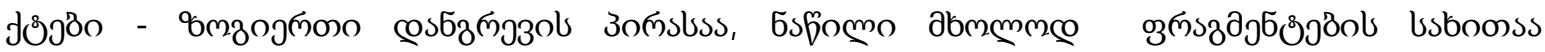

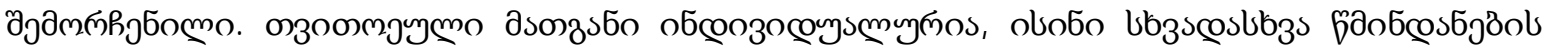

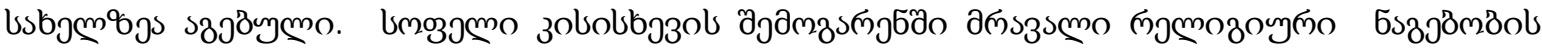

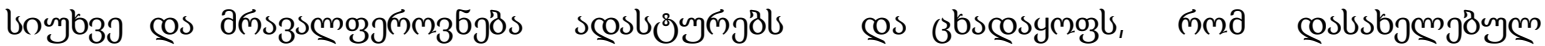

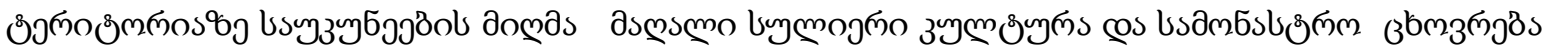

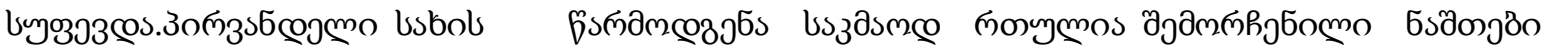

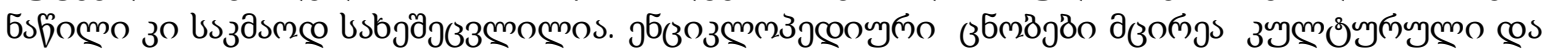

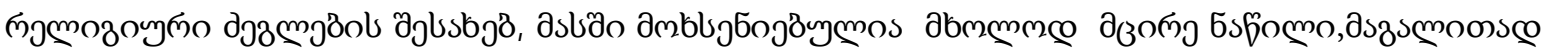

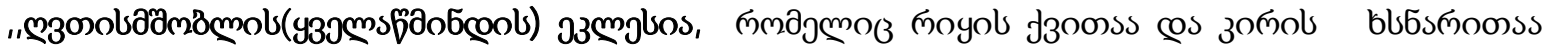

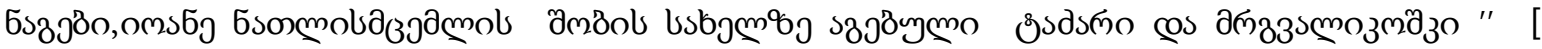

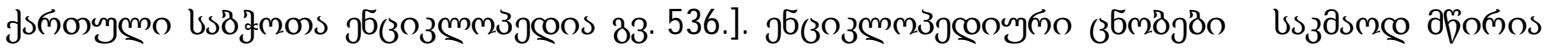

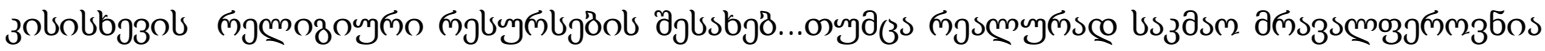

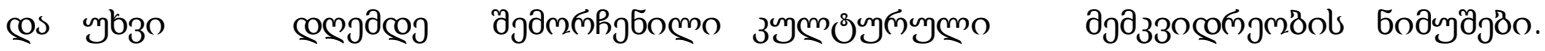

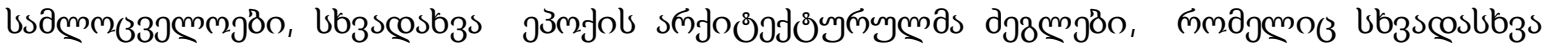

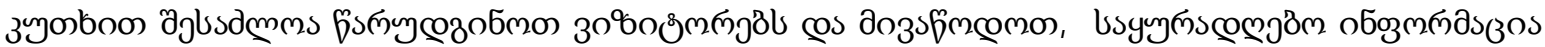

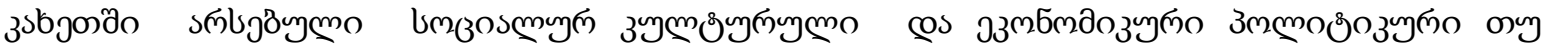

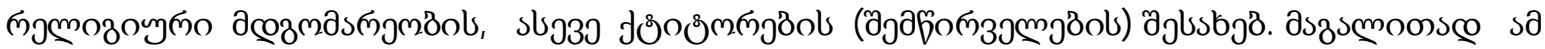

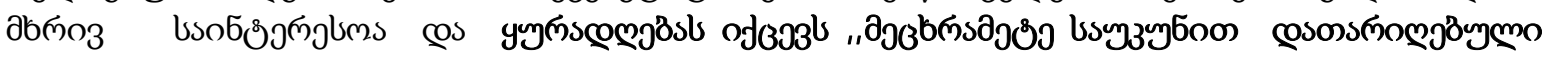

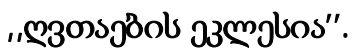

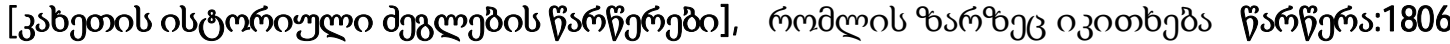

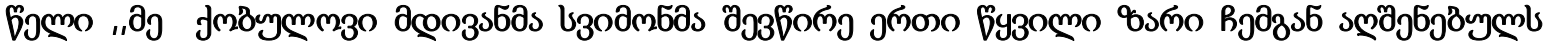

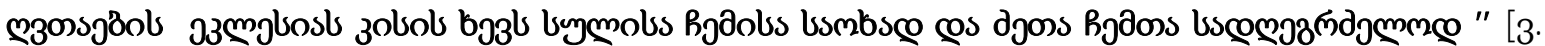

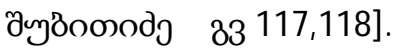

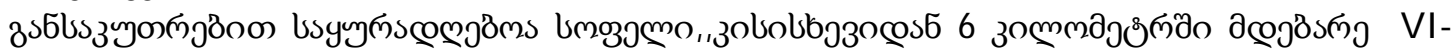

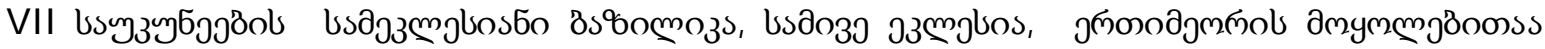

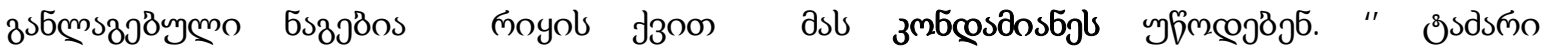

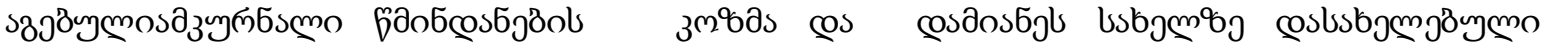

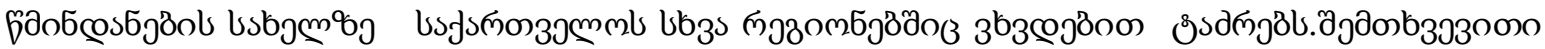

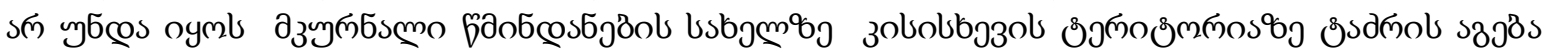

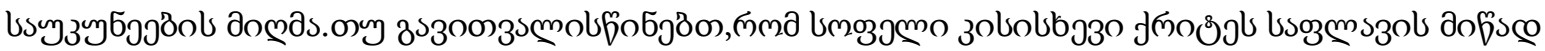

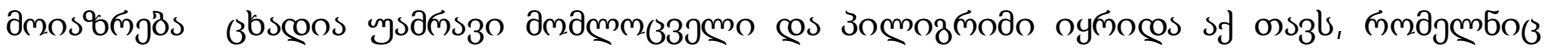

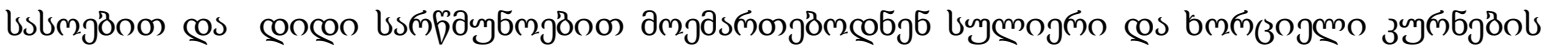

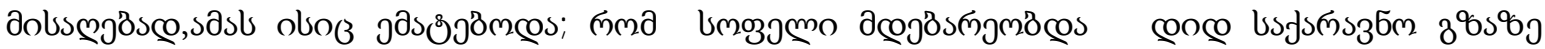

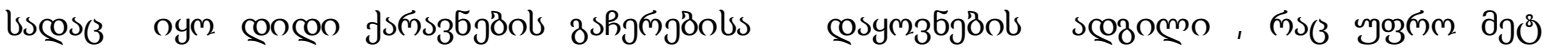

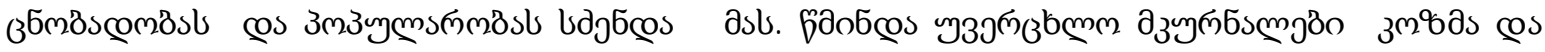




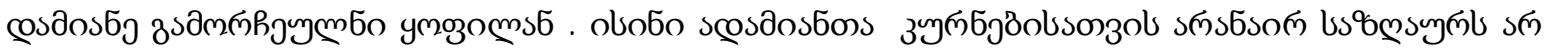

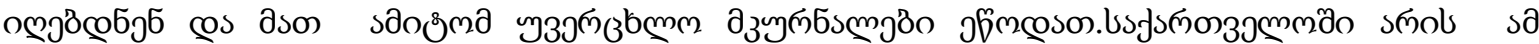

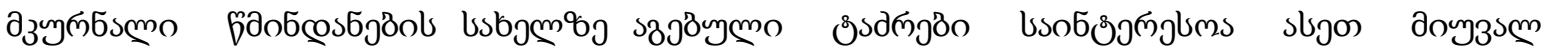

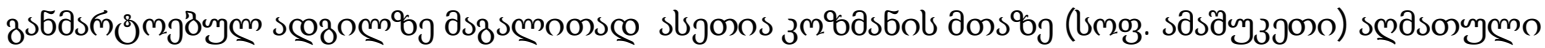

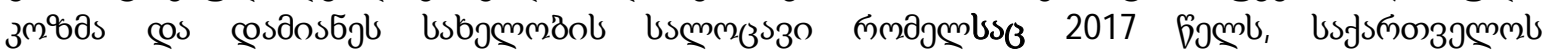

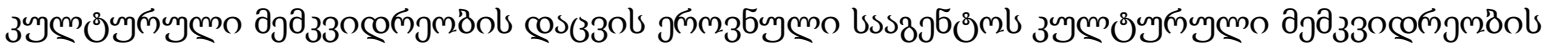

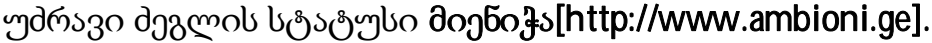

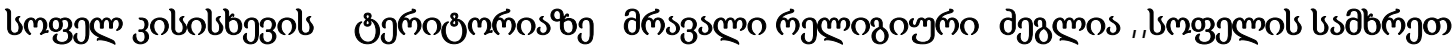
бsfom

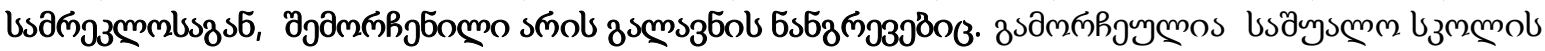

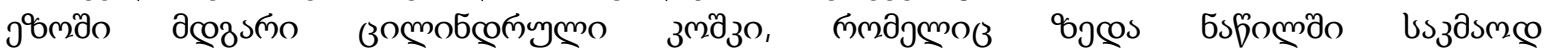

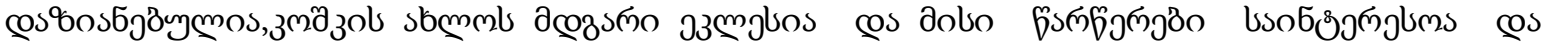

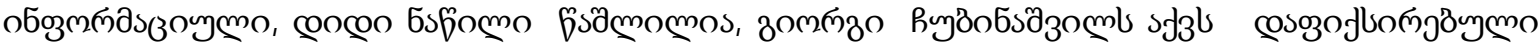

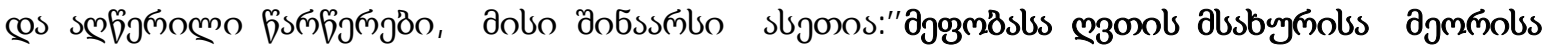

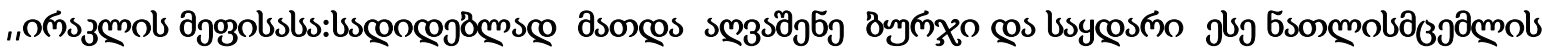

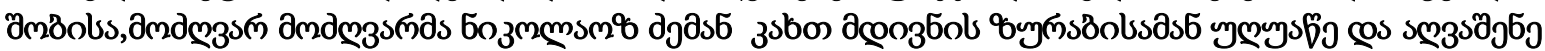

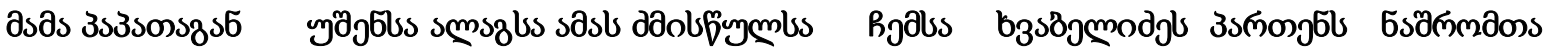

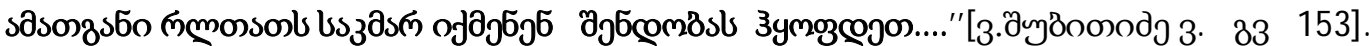

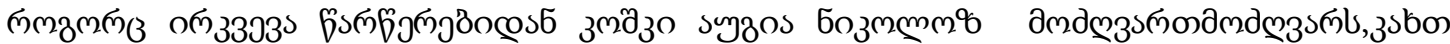

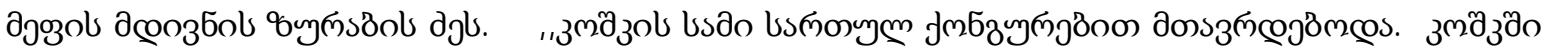

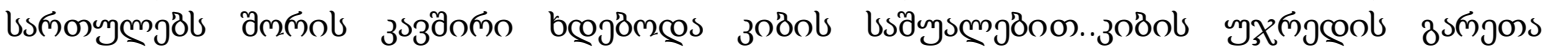

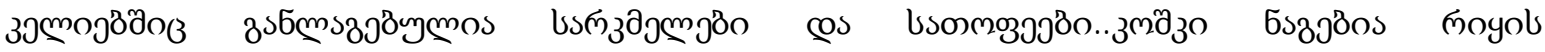

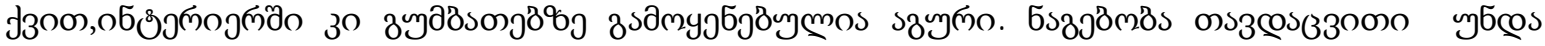

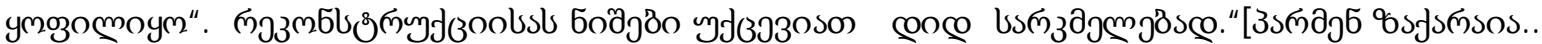

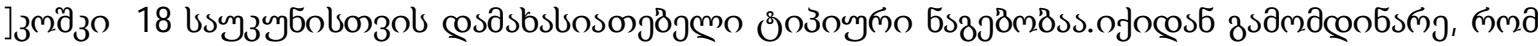

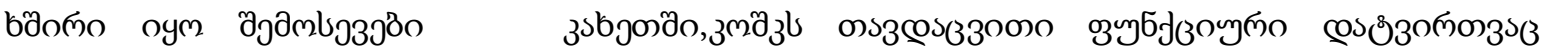

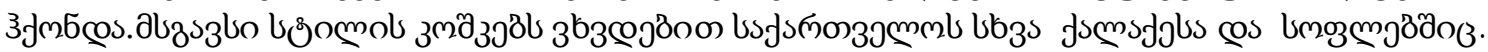

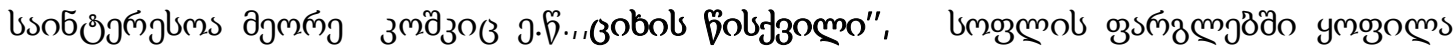

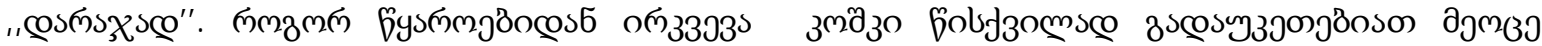

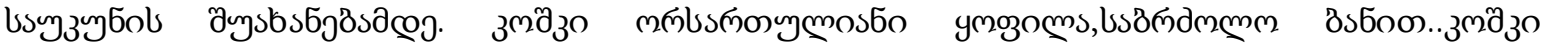

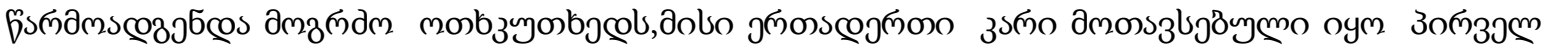

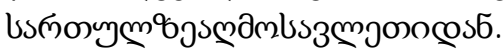

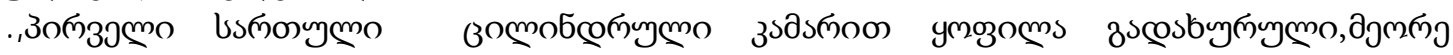

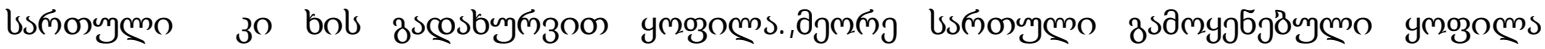

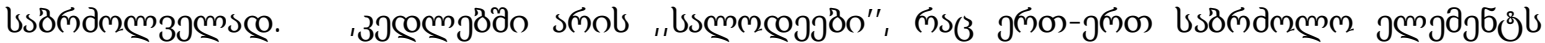

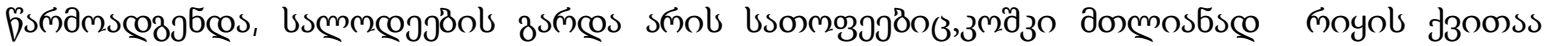

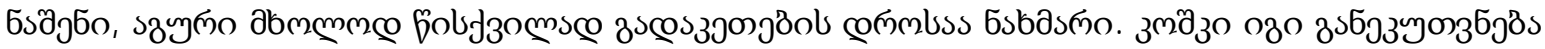

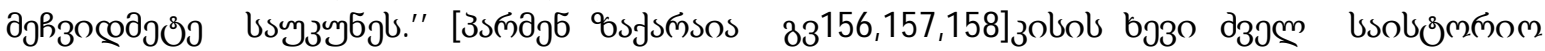

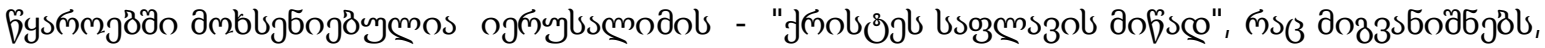

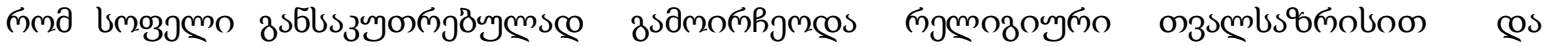

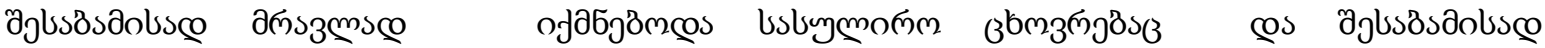

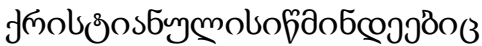

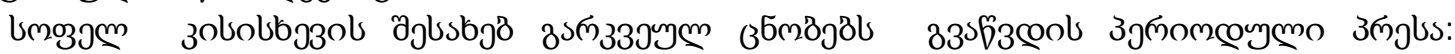

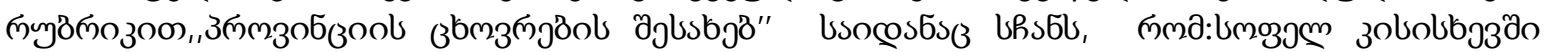

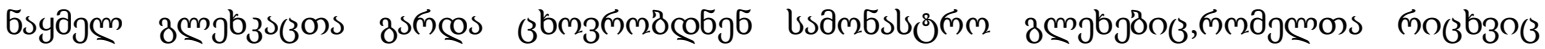

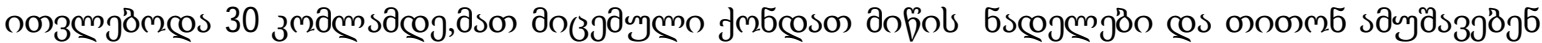

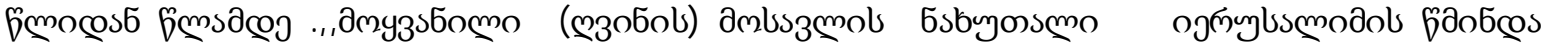

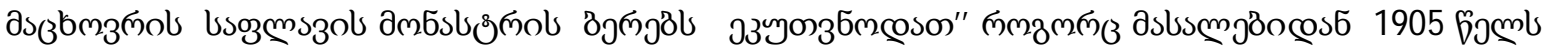

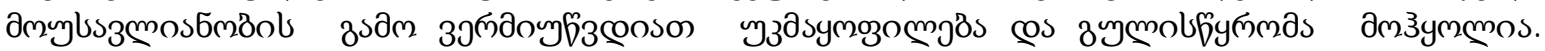

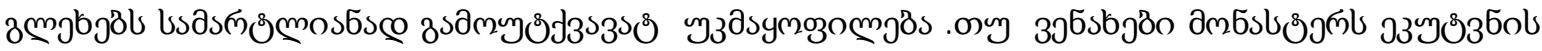




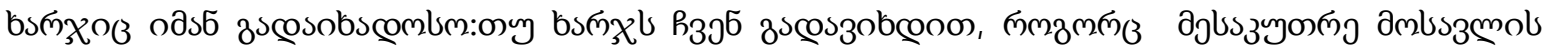

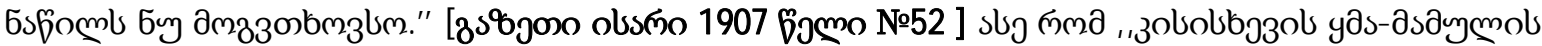

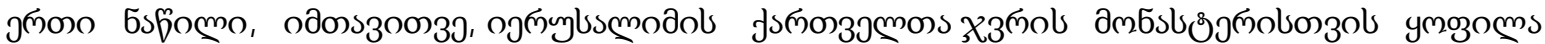

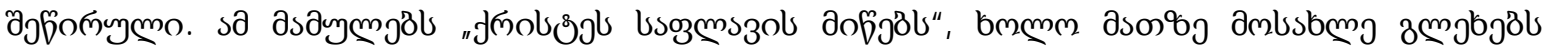

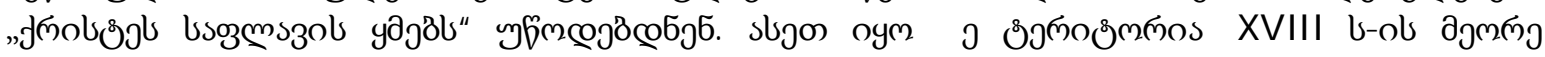

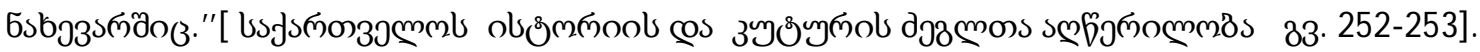

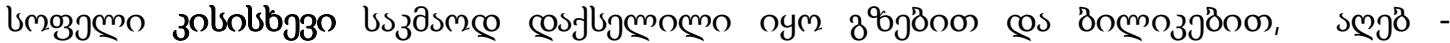

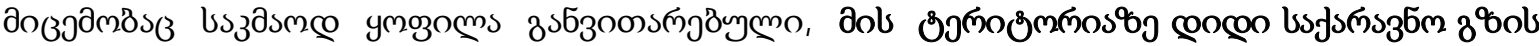

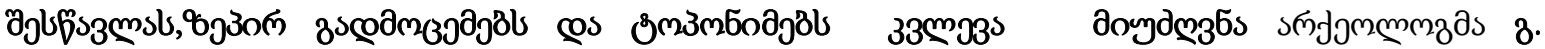

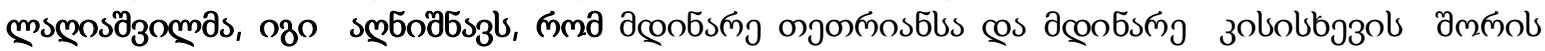

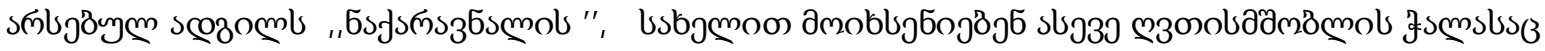

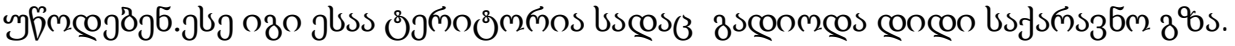

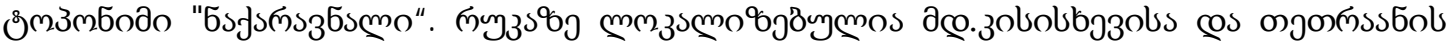

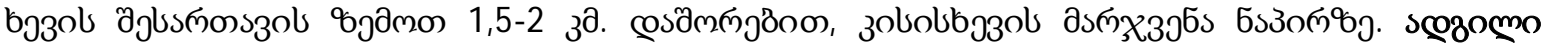

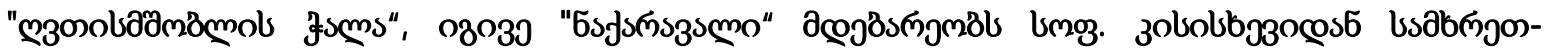

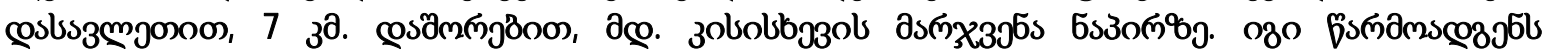

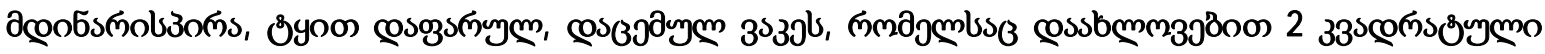

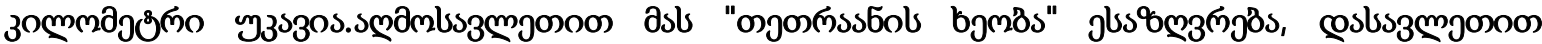

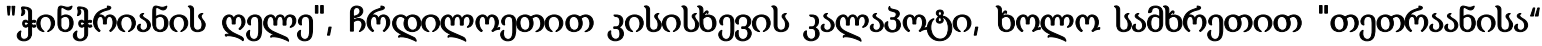

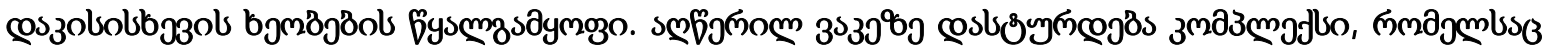

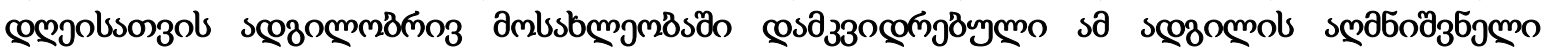

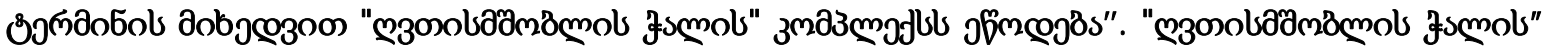

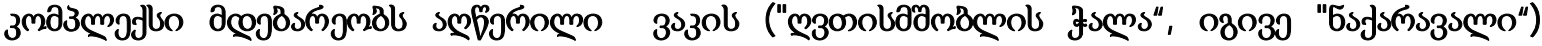

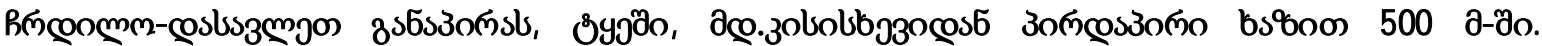

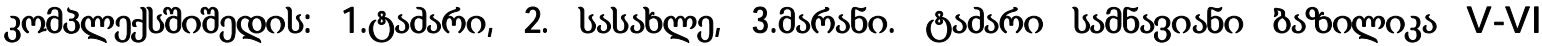

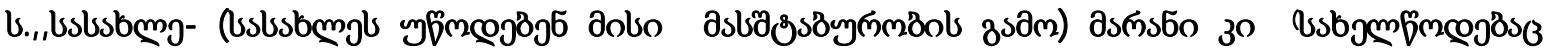

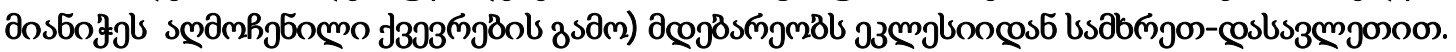

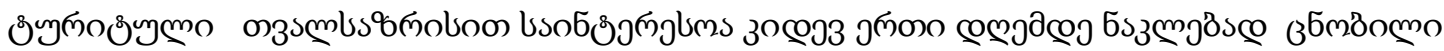

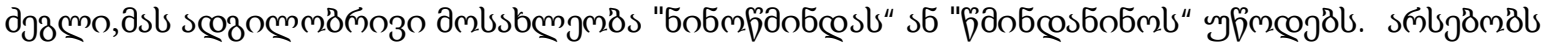

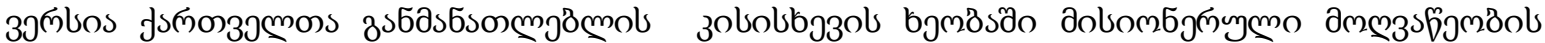

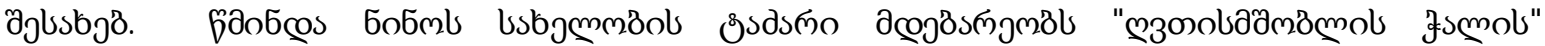
Bs\%omozocos6 bsabnjom-s

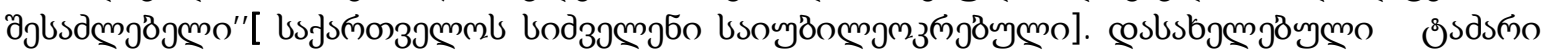

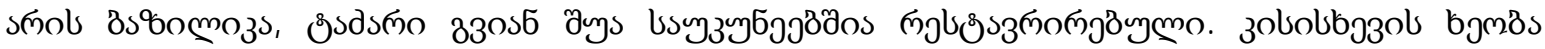

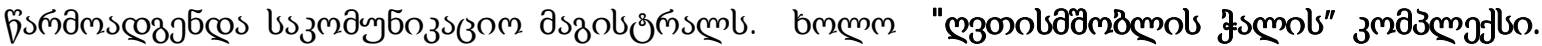

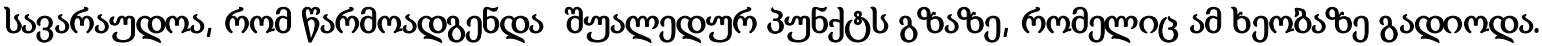

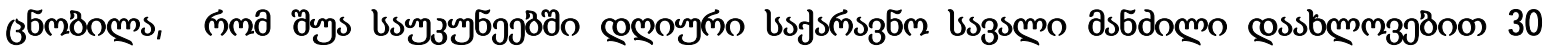

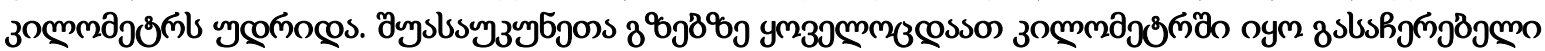

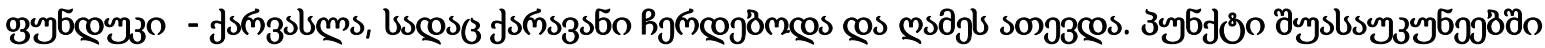

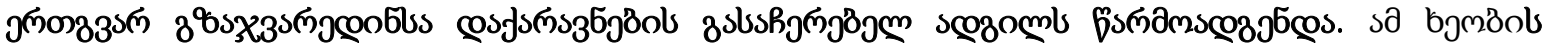

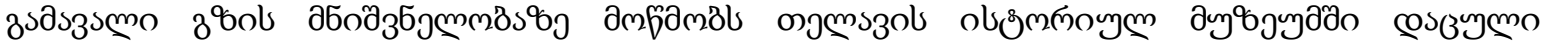

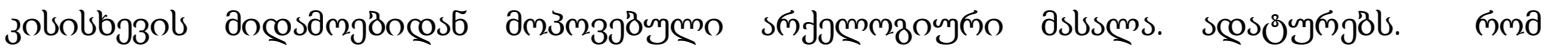

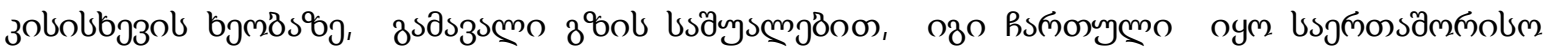

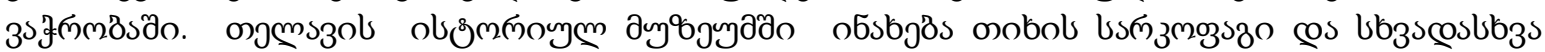

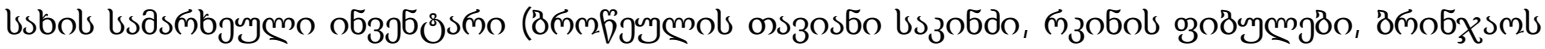

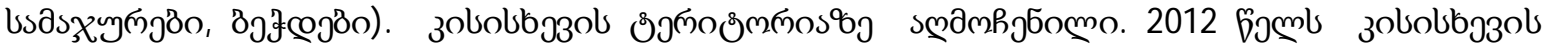

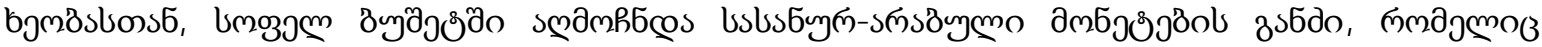

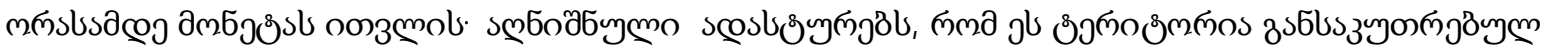

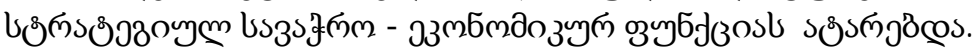




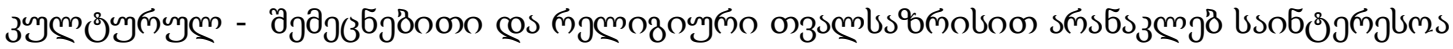

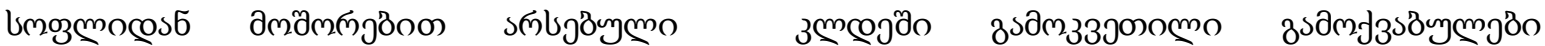

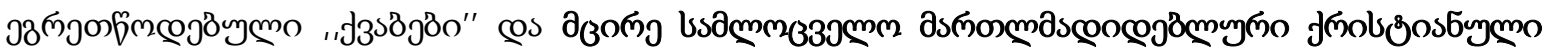

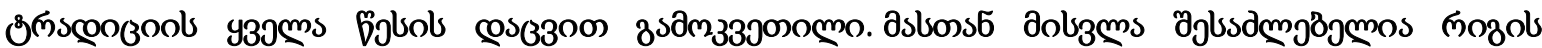

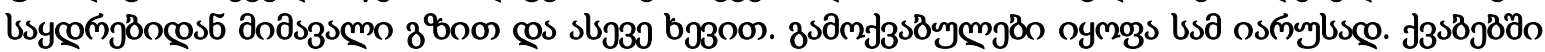

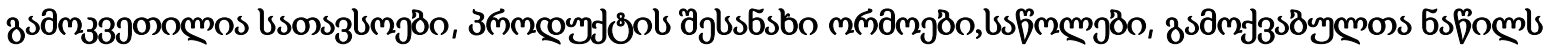

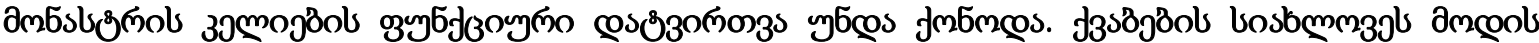

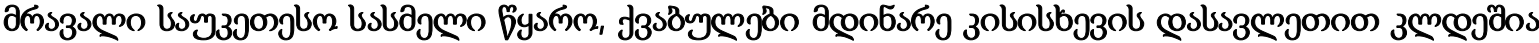

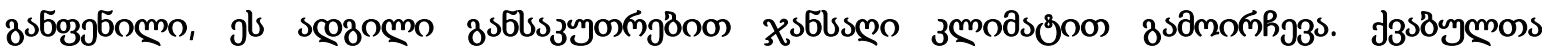

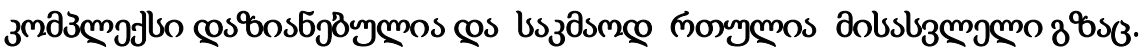

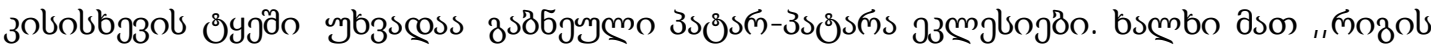

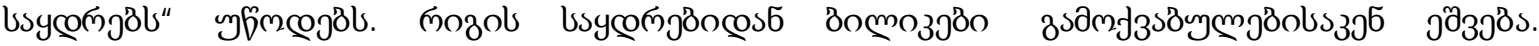

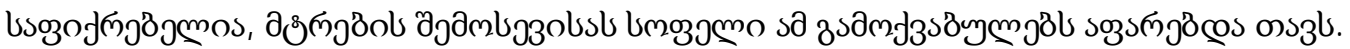

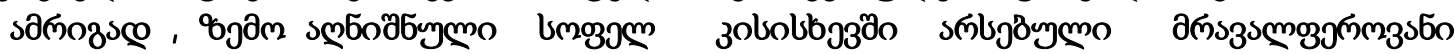

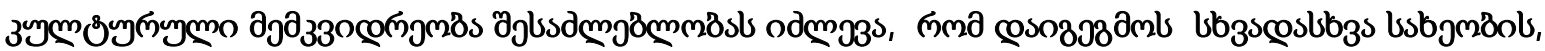
৮omo y

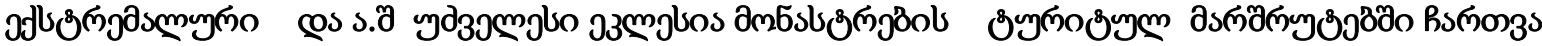

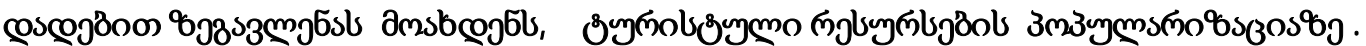

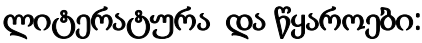

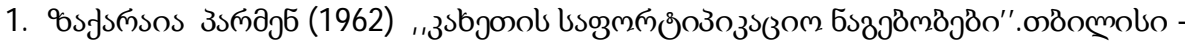

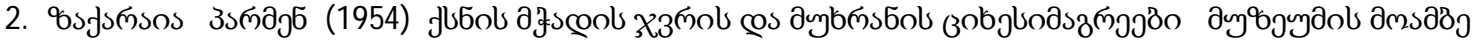
ठิman 18

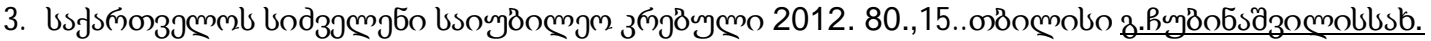

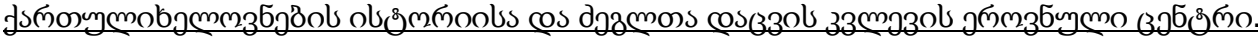

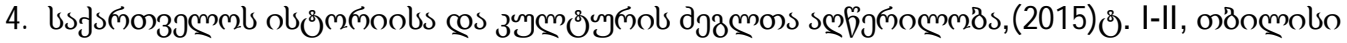

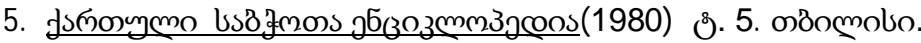

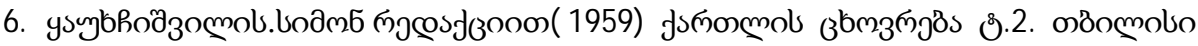

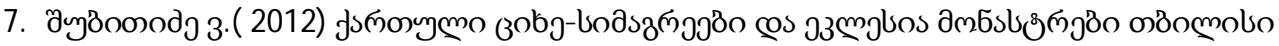

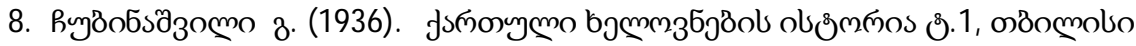

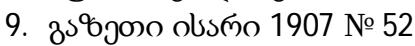

10.http://www.ambioni.ge/kozmanis-wm-giorgis-eklesas-zeglis-statsi-mieniwa

\title{
Village Kisiskhevi - the Best Resource for the Development of Cultural Tourism
}

Tamarashvili Tamar

Iakob Gogebashvili State University, Telavi

\begin{abstract}
Kakheti region is rich in abundance and diversity of tourist resources. The study and popularization of the tourism resources of each municipality is important for the cultural and economic development of both the region and each village. The article presents the multifaceted tourist opportunities in the territory of one of the ancient villages, Kisiskhevi, as a basis for tourism development. The unique cultural and religious objects in and around the village are analyzed, which make it possible to plan various tourist routes. Especially noteworthy is the "Ghvtismshoblis chalis" complex. The area "Nakaravnali" was an intermediate point on the road that passed through this valley. On the medieval roads, every thirty kilometers, there was a stop
\end{abstract}


for a caravan or caravanserai, where the caravan rested. The diverse cultural heritage of the village of Kisiskhevi provides an opportunity to plan tourist tours of different types, complexity and themes (cultural, cognitive, religious, extreme, etc). The involvement in the routes of the ancient churches and monasteries will have a positive impact on the promotion of tourist resources.

Keywords: tourism, Kisiskhevi, cultural heritage, prospects 